\title{
Cartography between reality and fiction: The maps by Albert Herrmann (1886-1945) of Chott el-Djerid
}

\author{
Petra Svatek \\ Austrian Academy of Sciences, Woldan Collection,petra.svatek@oeaw.ac.at
}

Keywords: History of Cartography, Albert Herrmann, Chott el-Djerid, Atlantis

\begin{abstract}
:
Between 1927 and 1934, the Berlin geographer Albert Herrmann (1886-1945), who taught historical geography at Frederick William University, published several papers, maps, sketches and views of the salt pan Chott el-Djerid, which is now in Tunisia (e.g. Fig. 1, 2). Herrmann came to the conclusion that the legendary island of Atlantis described by Plato must once have been located in this salt pan, the ancient Triton Lake. So far, no in-depth research has been done on Herrmann as a person, nor on his publications and maps. The author is clearly breaking new scientific ground here, especially since Herrmann's maps not only depict what really exists, but also have mythological components. They are thus clearly to be classified between reality and fiction.

The lecture deals with Herrmann's research practice with special reference to his methods of data collection and evaluation, his research networks and the content of the maps as well as their political context. The study is based on an analysis of maps from the 1920s and 1930s as well as archival materials that are now available in the Secret State Archives Prussian Cultural Heritage Foundation and in the archives of the Humboldt University in Berlin. In addition, a content-critical analysis was made of articles Herrmann had published in the "Zeitschrift der Gesellschaft für Erdkunde zu Berlin" and in "Petermanns Mitteilungen".
\end{abstract}

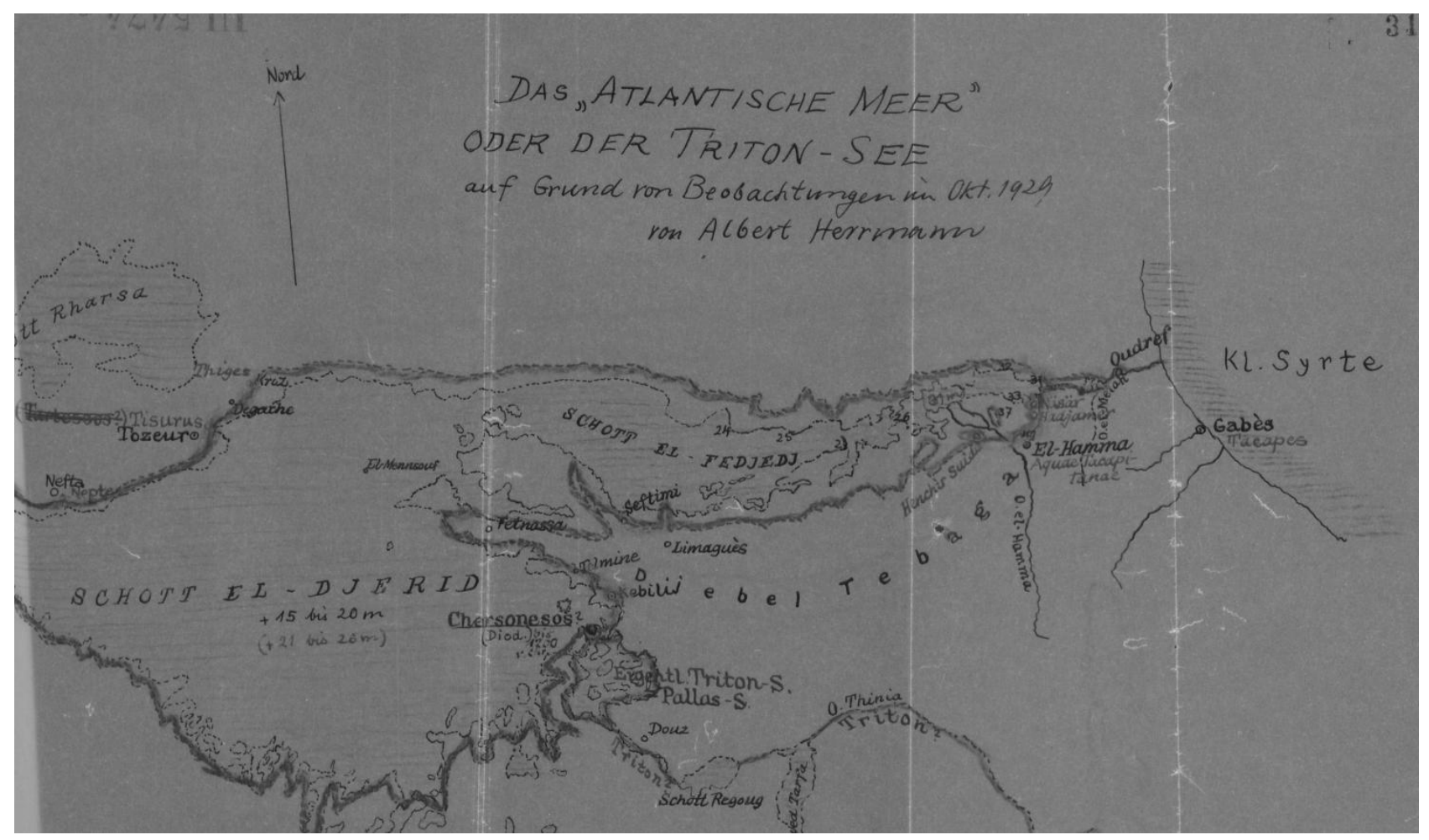

Figure 1. Section of the map Triton Lake: shorelines, rivers, settlements and ruins (GStA PK Berlin, I HA Rep. 76)

The maps and sketches were the result of several journeys to Chott el-Djerid, financed mainly by the Federal Ministry for Science, Art and Culture and the Emergency Association of German Science ("Notgemeinschaft der deutschen Wissenschaft"). Herrmann conducted field visits and mapping in conjunction with the study of ancient books and the 
Oera-Linda-Book. The Oera Linda Book describes in old Frisian mythological, religious and historical topics from 2100 BC onward. Today we know that the Oera-Linda-Book is a fake, written in the 19th century as a parody of the Holy Bible. Herrmann particularly emphasised the interdisciplinary character of his maps, as they presuppose geographical, prehistoric, ancient, archaeological and geological knowledge. In fact, his research unites many scientific disciplines. Geological mapping was as much a part of his research practice as the investigation of prehistoric and ancient historical sites, including the artefacts found there. Herrmann therefore cooperated with representatives of these fields of research, such as the British archaeologist Aurel Stein (1862-1943), the Austrian geographer Eugen Oberhummer (1859-1944), the Spanish ancient historian Pere Bosch i Gimpera (1891-1974) and the German papyrologist Friedrich Bilabel (1888-1945).

Although Herrmann also researched the physiogeographical features of the salt pan and was able to identify a beach terrace of the former Triton Lake as well as a fault line based on tectonic movements, his main focus was on the history of the region. Thus, his maps include not only settlements, rivers, wadis, ancient and recent shorelines, but also the location of ruins of ancient settlements, the sphere of influence of ancient culture and mythological entries in the form of position, line and area signatures. Herrmann's maps were based both on mapping and thus on scientific facts and on pure speculation. For example, while the sketch in Figure 1 shows the settlements, ruins, rivers, wadis and shorelines of the late 1920s as well as the ancient extent of Lake Triton, Figure 2 visualises, among other things, the location of Atlantis and the distribution area of the mythical Amazons people.

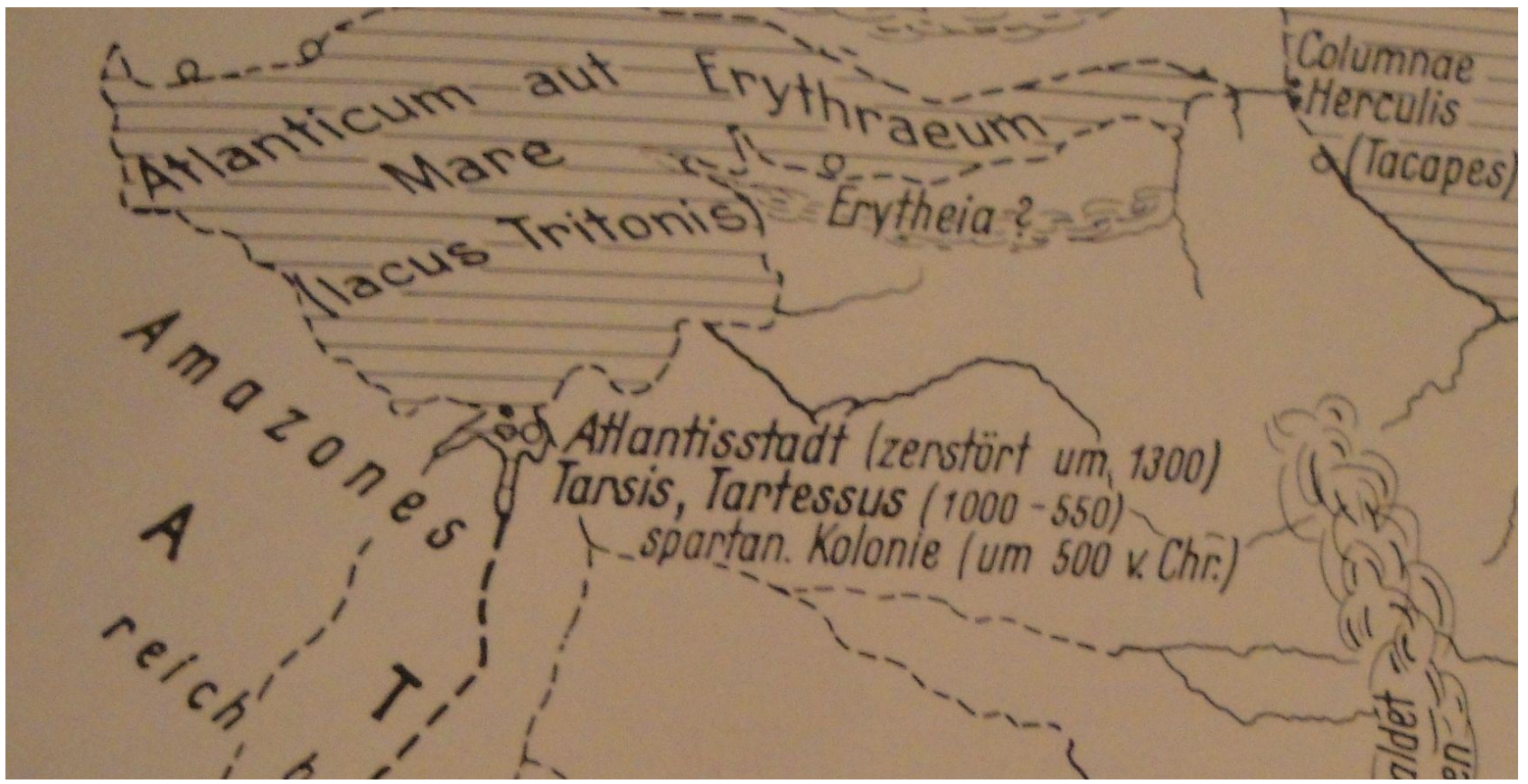

Figure 2. Section of the map "Chott el-Djerid until 550 BC" (Albert Herrmann, Unsere Ahnen und Atlantis, Berlin 1934, appendix)

Albert Herrmann's maps lead us to realise that a review of the truthfulness of maps from earlier decades and centuries is unavoidable. Of course, this must be brought into line with the state of knowledge at the time. But Herrmann could hardly convince other scientists of the interwar period with his theory about the location of the island of Atlantis. After the takeover of power of the National Socialist regime Herrmann finally aryanised his Atlantis theory. The inhabitants of Atlantis were for him members of a Nordic-Aryan race, who came from Friesland. He attested that the Germans had a high culture before Christianity, which fully corresponded to the Nazi ideology of the perfection of Aryan Germans. For this reason, Herrmann's theory degenerated into a kind of pseudoscience and was no longer pursued after 1945. His maps also fell into oblivion. 